\title{
Women in science
}

Claudia Torres Codeço 1

Claudia Mazza Dias 2

doi: $10.1590 / 0102-311 \times 00173718$
In 2018, women still only account for one third of university students enrolled in Science, Technology and Mathematics fields in the world 1. This difference tends to be even more striking among more advanced academic positions. Disincentives begin in childhood and continue over the course of the professional life, often so subtly that their effects are only noticed after the fact 2. Gender inequalities in science in Brazil, in particular in Mathematics, were the topic of the 1st Fluminense Meeting of Women in Biomathematics, which took place from August 15th to 17th, 2018 (http://dippg.cefet-rj.br/efmb). In addition to fostering debate, the meeting also sought to publicize the work of important Rio de Janeiro female Biomathematics researchers, an interdisciplinary field that is growing in Brazil, in which Mathematics are applied to issues from Biology, Medicine, Public Health and other fields. It had an excellent audience repercussion, with participants from 33 research and teaching institutions, including three from other countries, distributed among professors, researchers and students from primary education all the way to $\mathrm{PhD}$ candidates. The main theme was Mathematical Epidemiology, a field that seeks to use Mathematics to study the dynamics of transmissible diseases and their control. The studies presented at the encounter focused on dengue dynamics, vaccine interventions for varicella, yellow fever and influenza modeling and spatial distribution of leptospirosis, among others. The diverse methodologies show the insertion of female Brazilian researchers in fields such as stochastic and deterministic modeling, computational modeling, big data, etc.

The discussion of the gender imbalance in the sciences was carried out by specialists who presented a broad overview of the situation in the country. Professor Carolina Araújo, from Institute for Pure and Applied Mathematics (IMPA), emphasized that the discussion of gender in Mathematics has arrived late in Brazil, when compared with the rest of the world. She presented worrying numbers: while around half of Mathematics undergrads are women, this proportion drops to 20-30\% among graduate students. And the situation is not improving, she stated, while citing data from Brazilian Graduate Studies Coordinating Board (Capes). In the sciences, in general, 49\% are women; in Mathematics, only $21 \%$. Among the Brazilian National Research Council (CNPq) grant receivers, 36\% are women, considering all areas. The underrepresentation of women among not only authors, but especially editors and reviewers, was the subject of the March 2018 CSP Editorial 3, which
1 Programa de Computação Científica, Fundação Oswaldo Cruz, Rio de Janeiro, Brasil. 2 Instituto Multidisciplinar, Universidade Federal Rural do Rio de Janeiro, Nova Iguaçu, Brasil. 
cites that "in the field of mathematics, women represent only $15 \%$ of the researchers and are even less represented as editors, with only 10\%".

How can we reverse this trend? A common point to all discussions, and which seems to be the best immediate measure to combat this problem, is encouraging women scientists and professors to participate as role models in various events and initiatives, inspiring girls and showing that women's participation in science is a fact, despite stereotype threat and other phenomena, such as implicit bias, which leads young women from a young age to the false impression that they are less brilliant and capable when it comes to studies involving mathematical knowledge. Thus, this type of event, in addition to promoting the visibility of female work in the sciences, also help to strengthen Rio de Janeiro Biomathematics research groups and serve as an incentive for female participation in those groups, attracting women not only to Biomathematics, but to Mathematics and the sciences in general.

Another interesting fact presented at the event was the existence of thematic groups that encourage female participation in fields broadly perceived to be male-dominated. That is the case of "Girls in Robotics" (http://www.cefet-rj.br/), an initiative by the Federal Center for Technological Education Celso Suckow da Fonseca (Cefet/RJ - campus Nova Iguaçu) students; of "There are Girls in the Circuit" (https://temmeninanocircuito.wordpress. com/), coordinated by professors from the Physics Institute, Federal University of Rio de Janeiro (UFRJ); and of the "Women in Mathematics Project" (http://mulheresnamatemati ca.sites.uff.br/), an outreach action that maintains a site with up-to-date information about events and academic-scientific work carried out by women mathematicians in Brazil. We hope other initiatives will join these, contributing to the diffusion of female work in the sciences.

1. United Nations Educational, Scientific and Cultural Organization. Women and girls' education - facts and figures. http://www.unesco. org/new/en/unesco/events/prizes-and-cel ebrations/celebrations/international-days/ international-womens-day-2014/women-edfacts-and-figure/ (accessed on 03/Sep/2018).

2. Maxmen A. Why it's hard to prove gender discrimination in science. Lack of transparency and unconscious biases make it hard to spot inequality. Nature 2018; 15 may. https://www. nature.com/articles/d41586-018-05109-w.
3. Carvalho MS, Coeli CM, Lima LD. Women in the world of science and scientific publishing. Cad Saúde Pública 2018; 34:e00025018. 